\title{
Development of Glass/Jute Fibers Reinforced Polyester Composite
}

\author{
Amit Bindal, ${ }^{1}$ Satnam Singh, ${ }^{2}$ N. K. Batra, ${ }^{1}$ and Rajesh Khanna ${ }^{1}$ \\ ${ }^{1}$ Department of Mechanical Engineering, Maharishi Markandeshwar University, Mullana, Ambala 133203, India \\ ${ }^{2}$ Department of Mechanical Engineering, Thapar University, Patiala 147004, India
}

Correspondence should be addressed to Satnam Singh; satnam.mmu@gmail.com

Received 13 August 2013; Accepted 18 September 2013

Academic Editors: A. Kajbafvala and R. Uppaluri

Copyright (c) 2013 Amit Bindal et al. This is an open access article distributed under the Creative Commons Attribution License, which permits unrestricted use, distribution, and reproduction in any medium, provided the original work is properly cited.

\begin{abstract}
Composites play significant role as engineering material and their use has been increasing day by day due to their specific properties such as high strength to weight ratios, high modulus to weight ratio, corrosion resistance, and wear resistance. In present work, an attempt is made to hybridize the material using synthetic (glass) as well as natural fibres (chemically treated jute), such that to reduce the overall use of synthetic reinforcement, to reduce the overall cost, and to enhance the mechanical properties. All composite specimens with different weight percentages of fibres were manufactured using hand lay-up process and testing was done by using ASTM standards. Experimental results revealed that hybridization of composite with natural and synthetic fibres shows enhanced tensile strength, flexural strength, and impact strength. The content of natural reinforcement was found to be in the range of $25-33.3 \%$ for best results. The effect of treated jute on flexural properties was more than that on tensile properties, which was due to greater stiffness of jute fibers. Chemical treatment of jute fibers lowers the water absorption and results were comparable to glass fiber reinforced polyester composites. The addition of jute also reduced the overall cost by $22.18 \%$.
\end{abstract}

\section{Introduction}

The advancement in the field of material science led to many new and advanced materials. Composites are one of them, which are adopted in various engineering applications. Many authors [1-3] stated many properties of polymer reinforced plastics which makes them suitable for a variety of applications such as aerospace structures, automotive parts, and marine structures. The extensive use of composites in these industries is due to their combined properties of resilience, creep resistance, high strength and stiffness to weight ratios, corrosion resistance, and good damping properties. The study [4] showed that the use of natural fibre as reinforcement had increased many folds in recent years due to new environmental rules and customer demands. The increased demand of natural fibre is due to their low cost, low density, biodegradability, renewability, and abundance. The findings of this study [5] showed that the use of natural fibre can be enhanced by proper chemical treatment of fibres which produces better mechanical properties than untreated fibres. The properties of hybrid composites were studied by many researchers [6-8] and they concluded that hybrid composite offers greater resistance to water absorption, cost saving, weight saving, and increased properties. In present work, hybrid composites were manufactured with different weight fractions of reinforcement and with different weight percentages of different fibres. These specimens were tested according to the procedure mentioned in ASTM standards. The effect of natural fibre reinforcement on glass fibre reinforced composite was studied and mechanical properties were analyzed.

\section{Experimental}

2.1. Materials. The composite material used in this research was manufactured using plain weave mat of E-glass fabrics of $0.3 \mathrm{~mm}$ thickness as synthetic reinforcement. Jute fibres were used as natural reinforcement and they were dipped for 10 minutes in $10 \%$ of $\mathrm{NaOH}$ solution for chemical treatment as stated by Rokbi et al. [5]. The matrix material was polyester resin, which is thermoplastic resin and was supplied by Sakshi Dyes \& Chemicals, New Delhi, India. 
TABLE 1: Experimental results for tensile testing of composites.

\begin{tabular}{|c|c|c|c|c|}
\hline \multirow[b]{2}{*}{ Sr. no. } & \multirow{2}{*}{$\begin{array}{l}\text { Total weight percentage of } \\
\text { reinforcement in composite }\end{array}$} & \multicolumn{2}{|c|}{ Weight percentage of fibers } & \multirow[b]{2}{*}{ Tensile strength $\left(\mathrm{N} / \mathrm{mm}^{2}\right)$} \\
\hline & & $\begin{array}{c}\text { Jute } \\
\%\end{array}$ & $\begin{array}{c}\text { Glass } \\
\% \\
\end{array}$ & \\
\hline \multirow{3}{*}{1} & \multirow{3}{*}{$20 \%$} & 0 & 20 & 62.2 \\
\hline & & 10 & 10 & 63.35 \\
\hline & & 20 & 0 & 36.4 \\
\hline \multirow{5}{*}{2} & \multirow{5}{*}{$30 \%$} & 0 & 30 & 68.8 \\
\hline & & 10 & 20 & 74.59 \\
\hline & & 15 & 15 & 54.68 \\
\hline & & 20 & 10 & 43.84 \\
\hline & & 30 & 0 & 41.2 \\
\hline \multirow{5}{*}{3} & \multirow{5}{*}{$40 \%$} & 0 & 40 & 85.69 \\
\hline & & 10 & 30 & 95.85 \\
\hline & & 20 & 20 & 69.98 \\
\hline & & 30 & 10 & 59.02 \\
\hline & & 40 & 0 & 45.69 \\
\hline
\end{tabular}

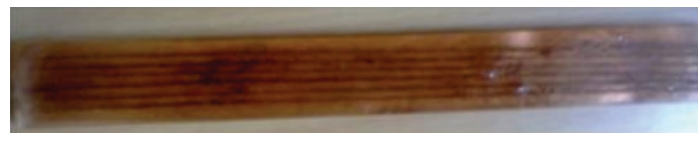

(a)

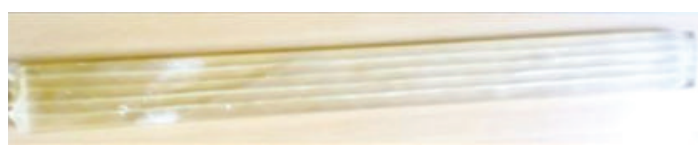

(b)

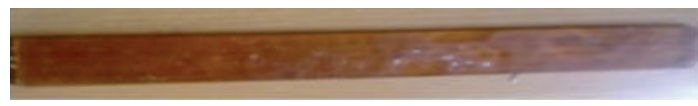

(c)

Figure 1: (a) Jute fiber reinforced composite, (b) glass fiber reinforced composite, and (c) hybrid composite consisting jute and glass fibers.

2.2. Composite Manufacturing Method. There are many techniques available in industries for manufacturing of composites such as compression molding, vacuum molding, pultruding, and resin transfer molding. The hand lay-up process of manufacturing [9] is one of the simplest and easiest methods for manufacturing composites. A primary advantage of the hand lay-up technique is to fabricate very large, complex parts with reduced manufacturing times. Additional benefits are simple equipment and tooling that are relatively less expensive than other manufacturing processes. All composite specimens were manufactured using hand lay-up process. The prepared specimens are shown in Figure 1.

2.3. Experimental Procedure and Apparatus. All experimental tests were carried out at Central Institute of Plastic Engineering and Technology (CIPET), Murthal, India.

Tensile tests were carried out on rectangular specimens of dimensions $165 \times 19 \times 4 \mathrm{~mm}$ at room temperature, by the method described in ASTM D638 on Autograph machine. Composite specimens were placed in the grips and were pulled at a speed of $5 \mathrm{~mm} / \mathrm{min}$ until failure occurred. The strain gauge was used to measure the displacement.

Flexural testing commonly known as three-point bending testing was also carried out on autograph machine as per ASTM D790. Composite specimens of dimensions $130 \times 12 \times$ $4 \mathrm{~mm}$ were horizontally placed on two supports and load was applied at the centre. The deflection was measured by the gauge placed under the specimen, at the centre.

Impact testing was carried out on Tinius Olsen machine as per procedure mentioned in ASTM D256. Composite specimens were placed in vertical position (Izod Test) and hammer was released to make impact on specimen and CRT reader gives the reading of impact strength.

Water absorption test was conducted as per ASTM D570. The specimens were first dried in oven, cooled and initial weight was measured. These specimens were immersed in water for 24 hours at room temperature and were dried before final weight measurement.

All experimental tests were repeated three times to generate the data.

\section{Results and Discussions}

3.1. Mechanical Properties. Experimental results of tensile testing of various composites with different weight fractions of reinforcement are presented in Table 1. The results show that addition of natural fibre content in glass fibres increases the overall tensile strength of composites. However, natural fibre content should be lesser than synthetic fibre content. When chemically treated jute was added in the range of $33.3 \%$ and $25 \%$ for total reinforcement of $30 \%$ and $40 \%$ (Table 1), it supports the glass fibres and tensile strength was increased by $8.41 \%$ for $30 \%$ and by $11.85 \%$ for $40 \%$ reinforced hybrid composite than glass fibre reinforced composite and by $81.04 \%$ to $109.7 \%$ for jute reinforced composites. This 
TABLE 2: Experimental results for flexural testing of composites.

\begin{tabular}{|c|c|c|c|c|}
\hline \multirow[b]{2}{*}{ Sr. no. } & \multirow{2}{*}{$\begin{array}{l}\text { Total weight percentage of } \\
\text { reinforcement in composite }\end{array}$} & \multicolumn{2}{|c|}{ Weight percentage of fibers } & \multirow[b]{2}{*}{ Flexural strength $\left(\mathrm{N} / \mathrm{mm}^{2}\right)$} \\
\hline & & $\begin{array}{c}\text { Jute } \\
\%\end{array}$ & $\begin{array}{c}\text { Glass } \\
\% \\
\end{array}$ & \\
\hline \multirow{3}{*}{1} & \multirow{3}{*}{$20 \%$} & 0 & 20 & 68.95 \\
\hline & & 10 & 10 & 71.32 \\
\hline & & 20 & 0 & 64.3 \\
\hline \multirow{5}{*}{2} & \multirow{5}{*}{$30 \%$} & 0 & 30 & 82.68 \\
\hline & & 10 & 20 & 95.35 \\
\hline & & 15 & 15 & 86.32 \\
\hline & & 20 & 10 & 90.00 \\
\hline & & 30 & 0 & 71.12 \\
\hline \multirow{5}{*}{3} & \multirow{5}{*}{$40 \%$} & 0 & 40 & 86.45 \\
\hline & & 10 & 30 & 102.83 \\
\hline & & 20 & 20 & 88.38 \\
\hline & & 30 & 10 & 84.32 \\
\hline & & 40 & 0 & 82.45 \\
\hline
\end{tabular}

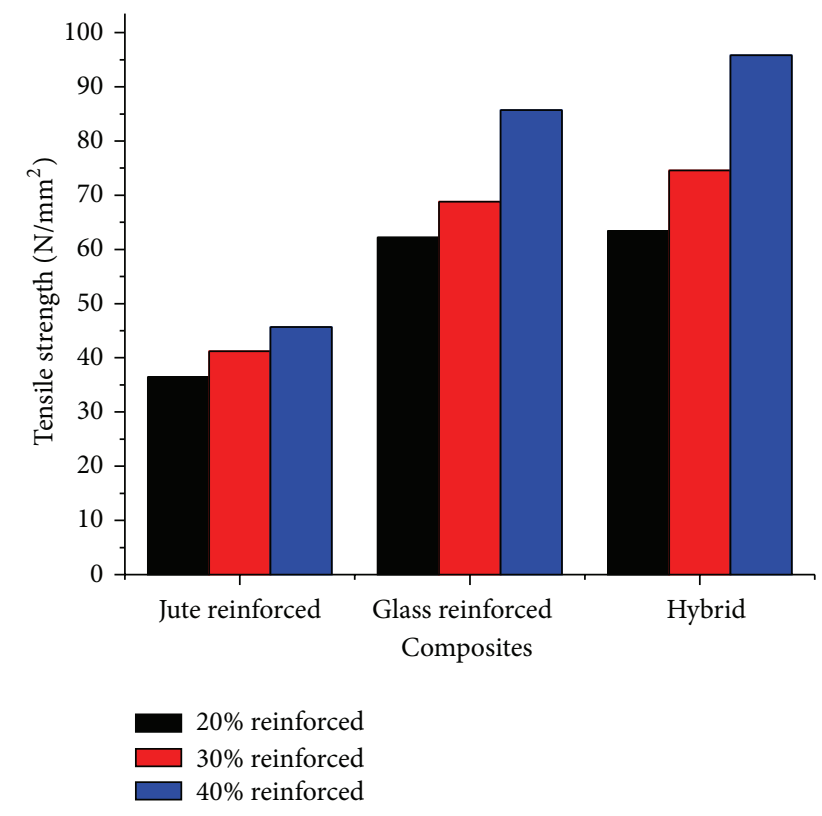

FIGURE 2: Comparison of tensile strength of various composites.

increase in composite strength was due to increased fibrematrix interface for chemically treated jute. However, for $20 \%$ reinforcement, contents of fibres were equally mixed to obtain best strength results. On further increasing jute reinforcement, the composite becomes more brittle as jute shows brittle behavior and overall strength decreases. The comparisons of tensile strength for different composites are shown in Figure 2.

The experimental results of flexural tests of composites with different weight fractions of reinforcement are presented in Table 2. Results revealed that both of the fibres showed good flexural strength in comparison to each other due to their stiffer behaviour and better fibre/matrix interfacial strength. However, addition of jute fibre in glass fibre reinforced polyester composites increased the flexural strength when its content was $33.33 \%$ and $25 \%$ with respect to glass fibres for 30 and $40 \%$ reinforced composites. In comparison to glass reinforced polyester, hybrid composite showed increased flexural strength by $15.32 \%$ to $18.94 \%$ than glass fibre reinforced composites and $34.06 \%$ to $24.71 \%$ in comparison to jute reinforced polyester composite. Increased reinforcement in the terms of jute greater than $33.33 \%$ and $35 \%$ in comparison of glass fibre produces weakening effect rather than strengthening. This is due to the less stiffness of jute fibres in comparison to glass and also matrix becomes insufficient to wet the increased natural fibre content. The comparisons of flexural strength for various composites are shown in Figure 3.

Impact tests are used in studying the toughness of material. Generally synthetic fibres produce interface having lower strength with matrix due to which energy absorption increases at these interfaces. A natural fibre exhibits greater fibre/matrix strength which does not allow energy to be absorbed at interfaces. Again experimental results revealed that small addition of jute increases the bonding capability and increases the area under stress strain curve and produces greater impact strength. On increasing the amount of jute content, which is more brittle than glass fibre, the overall brittleness of material increases and impact strength decreases. The experimental results of impact tests of composites with different weight fraction of reinforcement are presented in Table 3. On adding jute fibres in glass fibre reinforced polyester composites, the impact strength increased when content was $33.33 \%$. In comparison to glass reinforced polyester, hybrid composite showed increased impact strength by $8 \%$ to $12 \%$ in comparison to glass reinforced and $62 \%$ to $66 \%$ in comparison to jute reinforced polyester composite for $30 \%$ and $40 \%$ total reinforcement. Increased reinforcement in the content of jute fibers greater than $33 \%$ for total reinforcement of $30 \%$ of and $25 \%$ for total reinforcement of $40 \%$ in comparison to glass fibres the impact 
TABLE 3: Experimental results for impact testing of composites.

\begin{tabular}{|c|c|c|c|c|}
\hline \multirow[b]{2}{*}{ Sr. no. } & \multirow{2}{*}{$\begin{array}{l}\text { Total weight percentage of } \\
\text { reinforcement in composite }\end{array}$} & \multicolumn{2}{|c|}{ Weight percentage of fibers } & \multirow[b]{2}{*}{ Impact strength $\left(\mathrm{J} / \mathrm{m}^{2}\right)$} \\
\hline & & $\begin{array}{c}\text { Jute } \\
\%\end{array}$ & $\begin{array}{c}\text { Glass } \\
\% \\
\end{array}$ & \\
\hline \multirow{3}{*}{1} & \multirow{3}{*}{$20 \%$} & 0 & 20 & 114.23 \\
\hline & & 10 & 10 & 124.56 \\
\hline & & 20 & 0 & 73.56 \\
\hline \multirow{5}{*}{2} & \multirow{5}{*}{$30 \%$} & 0 & 30 & 165.23 \\
\hline & & 10 & 20 & 181.25 \\
\hline & & 15 & 15 & 156.63 \\
\hline & & 20 & 10 & 143.43 \\
\hline & & 30 & 0 & 115.35 \\
\hline \multirow{5}{*}{3} & \multirow{5}{*}{$40 \%$} & 0 & 40 & 212.36 \\
\hline & & 10 & 30 & 235.46 \\
\hline & & 20 & 20 & 190.26 \\
\hline & & 30 & 10 & 167.23 \\
\hline & & 40 & 0 & 143.96 \\
\hline
\end{tabular}

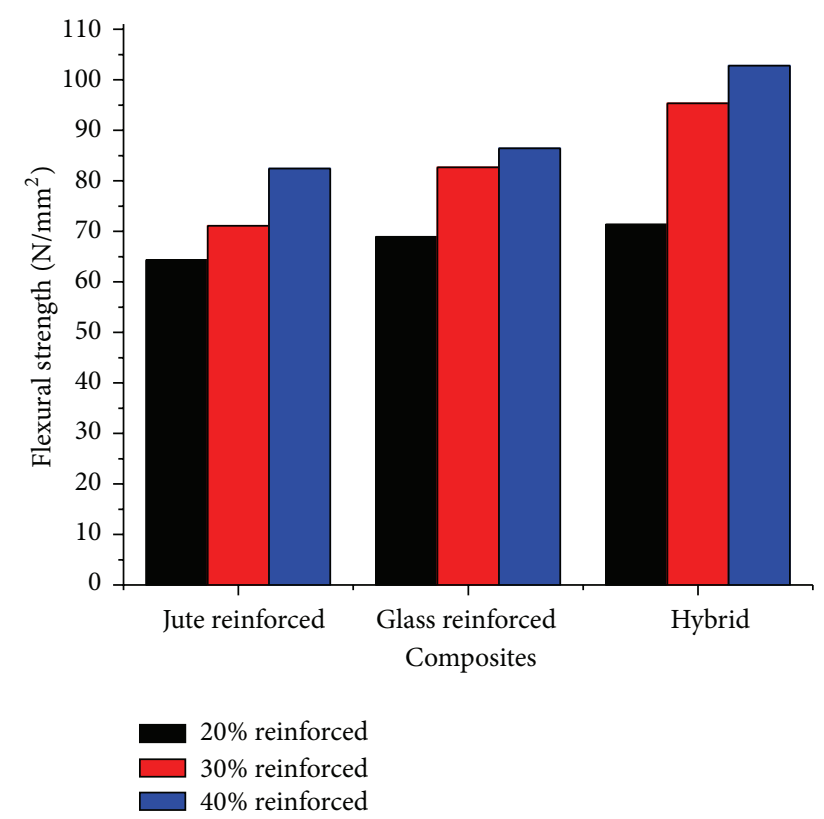

Figure 3: Comparison of flexural strength of various composites.

strength decreases. This decrease in impact strength is due to the increased brittleness and hardness of hybrid composites when jute content increases beyond this percentage (Table 3). The comparisons of impact strength of different composites are shown in Figure 4.

3.2. Water Absorption Test. The percentage of water absorbed by the composites was determined by finding the weight difference between samples, immersed in water and dry samples using [10]

$$
W(\%)=\left(\frac{W_{i}-W_{f}}{W_{i}}\right) \times 100 \%,
$$

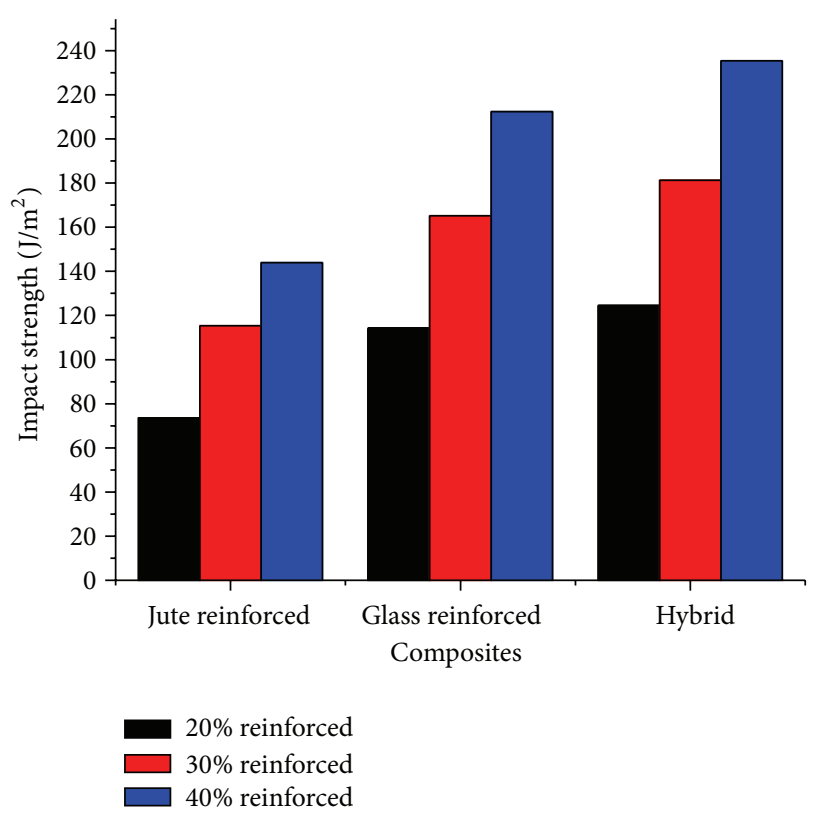

FIGURE 4: Comparison of impact strength of various composites.

where $W(\%)$ is the moisture content in percentage, $W_{f}$ is weight of wet samples, and $W_{i}$ is initial weight of samples. The results of water absorption tests are shown in Table 4.

The results of water absorption tests revealed that the amount of water absorbed by particular specimen depends upon the total weight percentage reinforcement in composite and weight percentage of jute fibers. When jute fibers were hybridized with glass fibers, the water absorption was reduced in comparison to jute fiber reinforcements. For $40 \%$ of total reinforcement, the water absorbed by $10 \%$ jute $+30 \%$ glass fiber reinforcements was almost the same for $40 \%$ of glass fiber reinforced composite. It further increases as jute content was increased from 10 to $40 \%$. For $30 \%$ 
TABLE 4: Water absorption results for composite specimens.

\begin{tabular}{|c|c|c|c|c|}
\hline \multirow[b]{2}{*}{ Sr. no. } & \multirow{2}{*}{$\begin{array}{l}\text { Total weight percentage of } \\
\text { reinforcement in composite }\end{array}$} & \multicolumn{2}{|c|}{ Weight percentage of fibers } & \multirow[b]{2}{*}{$W(\%)$} \\
\hline & & $\begin{array}{c}\text { Jute } \\
\%\end{array}$ & $\begin{array}{c}\text { Glass } \\
\%\end{array}$ & \\
\hline \multirow{3}{*}{1} & \multirow{3}{*}{$20 \%$} & 0 & 20 & 3.34 \\
\hline & & 10 & 10 & 3.42 \\
\hline & & 20 & 0 & 5.24 \\
\hline \multirow{5}{*}{2} & \multirow{5}{*}{$30 \%$} & 0 & 30 & 3.38 \\
\hline & & 10 & 20 & 3.51 \\
\hline & & 15 & 15 & 3.55 \\
\hline & & 20 & 10 & 3.68 \\
\hline & & 30 & 0 & 5.46 \\
\hline \multirow{5}{*}{3} & \multirow{5}{*}{$40 \%$} & 0 & 40 & 4.12 \\
\hline & & 10 & 30 & 4.21 \\
\hline & & 20 & 20 & 4.46 \\
\hline & & 30 & 10 & 5.28 \\
\hline & & 40 & 0 & 6.58 \\
\hline
\end{tabular}

reinforcement, the water absorbed by $10 \%$ jute $+20 \%$ glass was nearly equal as compared to pure glass reinforced polyester composite. For $10 \%$ jute hybrid reinforcements, the value of percentage water absorbed was nearly equal to glass fiber reinforced composites. This increased absorption of water by jute is due to its greater affinity towards water. However, these results are much better than those of the untreated jute which has greater affinity towards moisture content than treated jute. This behavior of alkali-treated jute is due to better interfaces formed by it with polyester resin.

3.3. Cost Analysis. The costs of natural fibers are much less than the synthetic fibers due to the manufacturing techniques and processes required to process synthetic fibers. The price of fibers per kilogram as provided by the supplier is shown in Table 5. Above findings show that optimum range for natural jute fiber is around $30 \%$ of the total reinforcement. So for the ratio of $1: 3$ of natural and synthetic fibers, the cost analysis for one $\mathrm{kg}$ of reinforcement for making hybrid composite is shown in Table 6 which shows cost reduction of $22.18 \%$.

\section{Conclusion}

The effect of jute fibre on mechanical properties of glass fibre reinforced polyester composite was studied and it showed that by incorporating the optimum amount of natural fibres, the overall strength of synthetic fibre reinforced polyester composite can be increased and cost saving of more than $20 \%$ can be achieved. Results revealed that natural fibre content is limited up to $25-35 \%$ for $30 \%$ and $40 \%$ overall reinforcement. For $10 \%$ reinforcement, the natural fibre content can be increased up to $50 \%$ with respect to glass fibres. The increment in mechanical properties is due to the increased fibre/matrix interfacial strength of chemically treated jute fibres than glass fibres.
TABLE 5: Cost of fibers per kilogram.

\begin{tabular}{lc}
\hline Type of fibers & Price (INR)/Kg \\
\hline Glass fibers & $1500 / \mathrm{kg}$ \\
Jute fibers & $150 / \mathrm{kg}$ \\
\hline
\end{tabular}

TABLE 6: Cost analysis of composite for fibers ratio $1: 3$.

\begin{tabular}{lc}
\hline Weight of fibers & Price (INR) \\
\hline 250 gm of jute fiber & 37.25 \\
750 gm of glass fiber & 1125 \\
Total cost/kg & 1162.25 \\
Saving/kg (with respect to glass fibers) & 332.75 \\
\hline Percentage saving & $22.18 \%$ \\
\hline
\end{tabular}

Novelty Statement. To the best of author's knowledge, the development of glass/jute fibers reinforced polyester composite is studied by very few authors. However, the effect of contents of different percentage of fibers on various mechanical properties was not found in the literature. The present work focuses on determination of tensile strength, flexural strength, impact strength, and water absorption tests of hybrid composite at different weight percentages of reinforcements. The weight percentage was further varied among the synthetic fibers and natural fibers to obtain the optimum results.

\section{References}

[1] R. Chandra, S. P. Singh, and K. Gupta, "Damping studies in fiber-reinforced composites-a review," Composite Structures, vol. 46, no. 1, pp. 41-51, 1999.

[2] A. K. Haldar, S. Singh, and P. Prince, "Vibration characteristics of thermoplastic composite," in Proceedings of AIP conference, Jaipur, India, November 2011. 
[3] S. Singh, P. Kumar, and S. K. Jain, "An experimental and numerical investigation of mechanical properties of glass fiber reinforced polyester composites," Advanced Materials Letters, vol. 4, no. 7, pp. 567-572, 2012.

[4] E. F. Rodrigues, T. F. Maia, and D. R. Mulinari, “Tensile strength of polyester resin reinforced sugarcane bagasse fibers modified by estherification," Procedia Engineering, vol. 10, pp. 2348-2352, 2011.

[5] M. Rokbi, H. Osmania, A. Imad, and N. Benseddiq, "Effect of chemical treatment on flexural properties of natural fiber reinforced polyester composite," Procedia Engineering, vol. 10, pp. 2092-2097, 2011.

[6] S. M. Bleay and L. Humberstone, "Mechanical and electrical assessment of hybrid composites containing hollow glass reinforcement," Composites Science and Technology, vol. 59, no. 9, pp. 1321-1329, 1999.

[7] C. K. Subhash and J. K. Michael, "Thick-section AS4-graphite/ E-glass/PPS hybrid composites: part II. Flexural response," Composites Science and Technology, pp. 473-482, 1996.

[8] N. Venkateshwaran, A. Elayaperumal, and G. K. Sathiya, "Prediction of tensile properties of hybrid-natural fiber composites," Composites B, vol. 43, no. 2, pp. 793-796, 2012.

[9] J. P. Davim, P. Reis, and C. C. António, "Experimental study of drilling glass fiber reinforced plastics (GFRP) manufactured by hand lay-up," Composites Science and Technology, vol. 64, no. 2, pp. 289-297, 2004.

[10] Z. Salleh, Y. M. Taib, K. M. Hyie, M. Mihat, M. N. Berhan, and M. A. Ghani, "Fracture toughness investigation on long kenaf/woven glass hybrid composite due to water absorption effect," Procedia Engineering, vol. 41, pp. 1667-1673, 2011. 

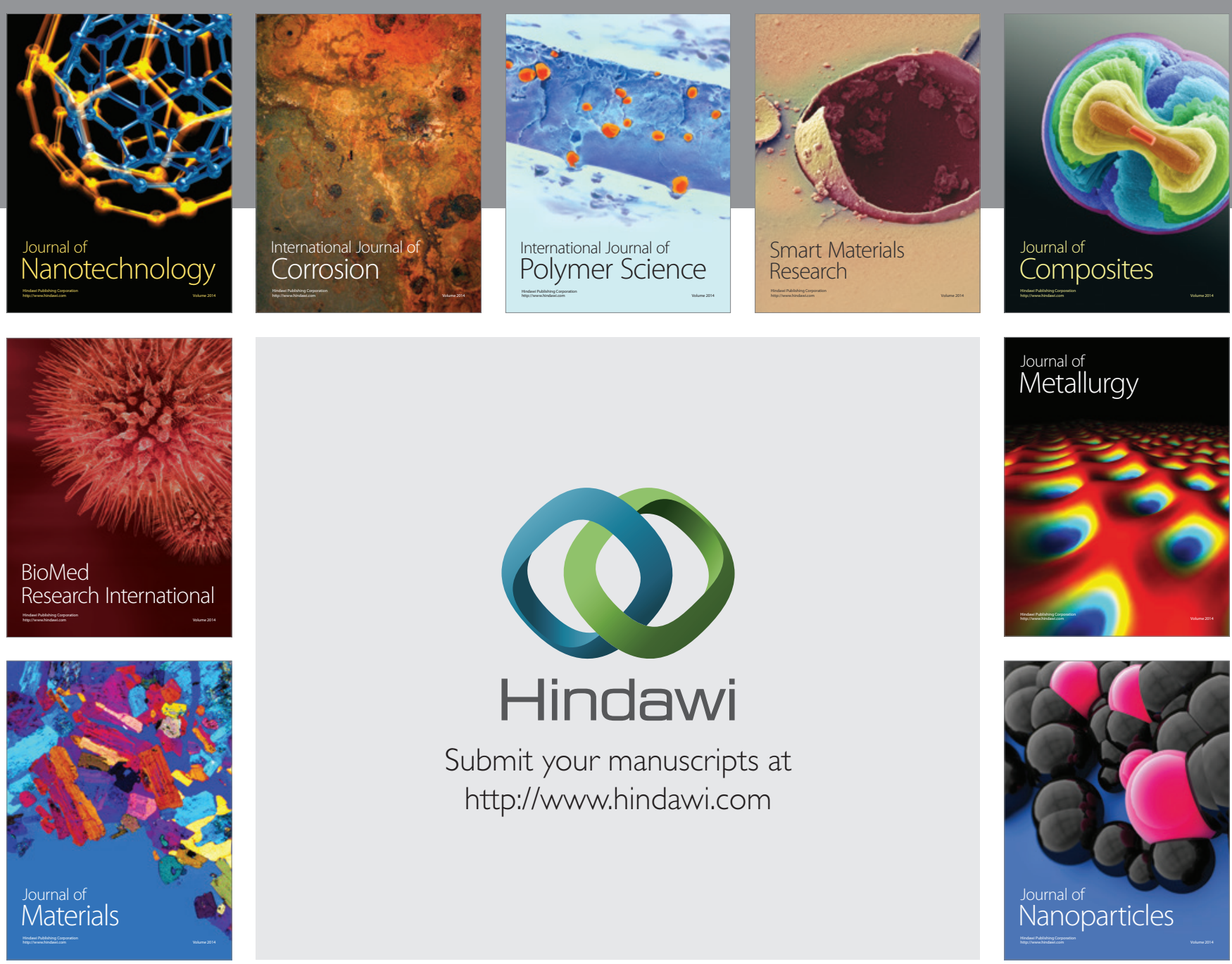

Submit your manuscripts at http://www.hindawi.com
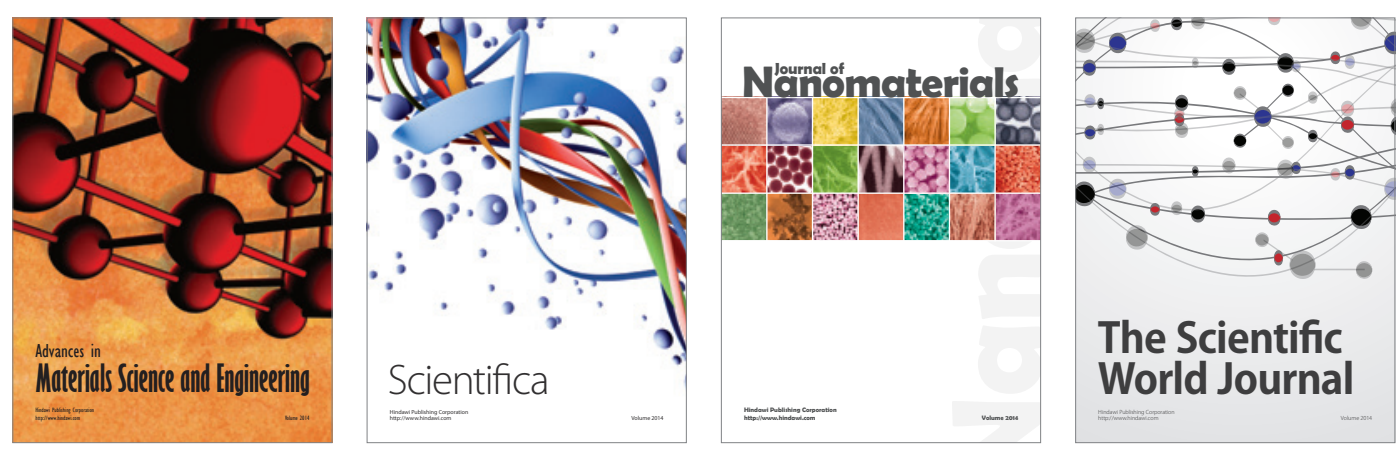

\section{The Scientific World Journal}
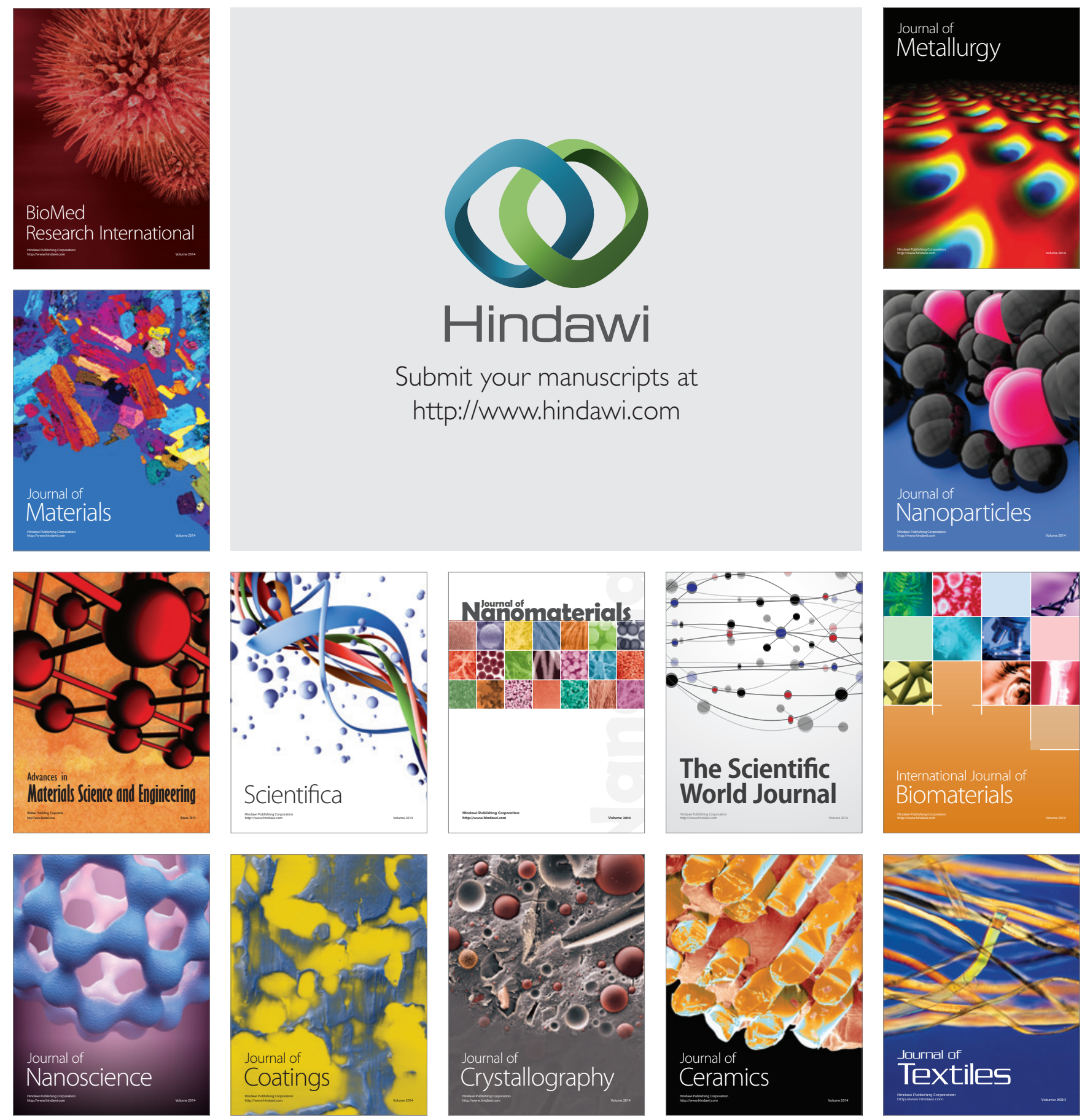